NASA Technical Memorandum 102387

AIAA-90-0048

\title{
Some Observations on Transitory Stall in Conical Diffusers
}

K.B.M.Q. Zaman and M.D. Dahl

Lewis Research Center

Cleveland, Ohio

Prepared for the 28th Aerospace Sciences Meeting sponsored by the American Institute of Aeronautics and Astronautics Reno, Nevada, January 8-11, 1990

\section{N/Sก}

(NASA-TM-102387) SIME ODSERVATIONS ON TRANSITIRY STALL IN CONICAL OIFFUSERS (NASA) $13 \mathrm{P}$ 


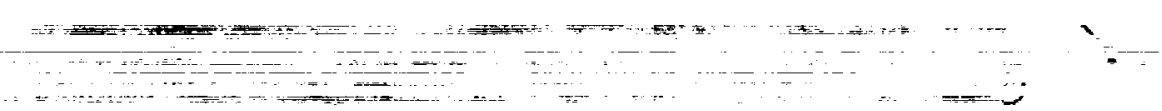

(1... $-\cdots+\cdots$

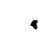


SOME OBSERVATIONS ON TRANSITORY STALL IN CONICAL DIFFUSERS

K.B.M.Q. Zaman and M.D. Dahl

National Aeronautics and Space Administration

Lewis Research Center

Cleveland, $\mathrm{OH} 44135$

\section{Abstract}

Results from an experimental investigation on the flow through conical diffusers are presented. The mean and fluctuating velocity fields are compared for three diffusers with total diffusion angles of $16^{\circ}, 20^{\circ}$ and $24^{\circ}$, in the throat Mach number $\left(M_{t}\right.$ ) range of 0.05 to 0.95 . Each of the diffusers were $14 \mathrm{~cm}$ long and had a $5.08 \mathrm{~cm}$ inlet diameter, and the flow exited into the ambient. The boundary layer at the throat was thin with the throat diameter $\left(D_{t}\right)$ to momentum thickness $(\theta)$ ratio being as nigh as 800 at $M_{t}=0.4$. While the $16^{\circ}$ diffuser flow exited with a top-hat mean velocity proflle, increasing losses due to increasing separation resulted in fuller profiles for the $20^{\circ}$ and $24^{\circ}$ cases. A detajled flowfleld study was conducted for the $16^{\circ}$ diffuser. The $u^{\prime}$-spectrum, measured at the exit plane, exhibited a peak apparently due to the ensuing jet column instability throughout the $M_{t}$ range covered. In addition, a much lower frequency spectral peak also occurred in the Mt range of 0.3 to 0.7 . Both of the spectral peaks were due to axisymmetric flow fluctuations. A self-sustaining flow oscillation occurred in the $M_{t}$ range of 0.6 to 0.85 , emitting a loud tone, when the jet column instability frequency matched the resonance frequency of the diffuser. Limited data showed that artificial acoustic excitation was effective in reducing the flow fluctuations, with a resultant increase in the pressure recovery, at low $M_{t}$.

\section{Introduction}

A diffuser is an important element in internal fluid machinery. There can be numerous situations where the designer may have to demand optimum pressure recovery within shortest possible lengths. This means operating near the brink of stall yet avoiding actual stall. This can be difflcult and risky as the flow involving incipient stall is not easily predictable. Such a flow is sensitive to operating conditions, e.g., to the mean velocity distribution, the turbulence intensity and spectrum, and the boundary layer state at the throat. 1-3 Moreover, such operating conditions may induce transitory stall which involves large unsteady fluctuations resulting in excessive loss and noise as well as large unsteady forces.

Transitory stall has been investigated primarily in two-dimenstonal diffusers, 4,5 and it is fair to say that the mechanisms of this class of flow in any flow geometry rema in very little understood. For lack of a clearer definition, we will consider any intermediate state between fuliy attached and fully stalled states to involve transitory stall. The present experimental program was initiated to study transitory stall in conical diffusers as well as its response to artificial acoustic excitation. The program is part of an overall effort in fiow control by artificial excltation at the NASA Lewis Research Center, 6 and was easily implemented in view of the availability of a sophisticated jet flow facility with provision for acoustic excitation. Several diffuser sections were built to fit a specially built nozzle piece. These provided flows with varying degrees of transitory stall. Limited experiments have been conducted so far, and this paper should be considered as a progress report of this program.

\section{Experimental Facllity}

Figure l(a) is a photograph of the experimental faclility which has been described in detail in Ref. 7. The flow, after passing through a large plenum, exited through a contoured nozzle. Each of the straight conical diffusers was attached to a flange at the end of the nozzle. A schematic of the essential parts of the flow facility is shown in Fig. $1(b)$. Three diffusers with totai diffusion angles $(\psi)$ of $16^{\circ}, 20^{\circ}$ and $24^{\circ}$ were used in the experiment. The nozzle end and the entrance to the diffusers were machined to provide a smooth junction. A cylindrical section, extending approximately $1.27 \mathrm{~cm}$ on elther side of the function. will be referred to as the "throat". The cylindrical section was smoothly faired into the beginning of the diffuser section. The diffuser section was $14 \mathrm{~cm}$ long; the exit diameters were 9.02, 10 and $11.02 \mathrm{~cm}$ for the $16^{\circ}, 20^{\circ}$ and $24^{\circ}$ cases, respectively. Also shown in Fig. I(b) are the acoustic drivers used for excitation purposes. A tap at the throat was used to measure the corresponding static pressure $\left(P_{s t}\right)$. Standard hot-wire and pitot-static measurements were made. Probe traverses and data acquisition were done by automated computer control.

\section{Results and Discussion}

\subsection{Comparison of the Three Diffusers}

Figure 2 shows the varlations of the total gauge pressure ( $P_{t t}$ ) and the static gauge pressure $\left(P_{s t}\right)$, measured at the throat, as a function of $M_{t}$. Note that $P_{s t}$ would be zero in the limiting case of a nozzle discharging as a jet and $P_{t t}$ would be zero in the ideal case of a diffuser with infinite expansion and full pressure recovery. For the case of finite expansion but full pressure recovery, Ptt should equal the dynamic pressure at the exit of the diffuser. The observed trends of $P_{\text {st }}$ and $P_{\text {tt }}$ ( $F$ ig. 2 ) with increasing diffusion angle are due primarily to increasing losses within the diffusers owing to increasingly separated flows. The variations of the corresponding pressure recovery coefficient $C_{p}$. approximated as $C_{p}=-P_{s t} /\left(P_{t t}-P_{s t}\right), 2$ are shown at the bottom of Fig. 2. The values of $C_{p}$ agree reasonably with data reported in the literature for corresponding diffuser geometries with thin inlet boundary layers.'

The mean velocity (U) proflles measured $3.5 \mathrm{~mm}$ downstream of the exit plane of the diffusers are shown in the upper part of Fig. 3. The mass fluxes 
computed from these profiles, normalized by the mass flux at the throat, are $1.03,1.14$ and 1.55 for the $16^{\circ}, 20^{\circ}$ and $24^{\circ}$ diffusers, respectively. The increasing fluxes are qualitatively reconciled by the fact that ambient air is ingested around the periphery by the transitory stall in the larger diffusers. However, the corresponding reverse flows introduced some errors in the hot-wite measurements, and thus, the measured fluxes should not be accurate for the larger diffusers. For the $16^{\circ}$ diffuser, however, the mass flux is nearly conserved, indicating insignificant amount of such error in that case. The lower part of Fig. 3 shows the corresponding root mean square velocity fluctuation ( $U^{\prime}$ ) profiles. Note that the data are normalized by the throat velocity $\left(U_{t}\right)$ and thus the intensitles normalized by the local velocities are much larger, e.g., about 0.32 in the core flow of the $24^{\circ}$ diffuser.

The streamwise variations of $U$ and $U^{\prime}$ along the axis are shown in $\mathrm{Fig} .4,\left(x / D_{t}=3\right.$ represents the exit plane). Consider the U-profile for the $16^{\circ}$ case which apparently involves negligible flow separation. If the flow expanded ideally. with a top-hat profile having a thin boundary layer. U/Ut would be expected to be about 0.32 at $x / D_{t}=3$. However, the measured value there is about 0.5 . The difference is due to a large boundary layer growth about which an idea can be obtained from $\mathrm{Fig} .3$ (further data are discussed later). The $24^{\circ}$ case involves the largest fluctuations occurring at the farthest upstream location; the initial rate of decrease of the ceterline mean velocity is the least for this case. Presumably. the flow in this diffuser separates shortly downstream of the throat and thus higher velocity is maintained around the axis. But farther downstream, the large fluctuations result in a faster decay of $U$. The $U^{*}$-profiles in Fig. 4 bear some resemblance to corresponding profiles in a free jet. 7 however, the flow evolution in the present cases is governed by the diffuser geometries which determine the imposed pressure gradient and the location of separation.

The spectra of the velocity fluctuations measured at the exit plane for the three diffusers at $M_{t}=0.3$ are shown in $F i g .5$. The ordinate scale is arbitrary (linear) and the amplitudes for the $16^{\circ}$ case are much lower than those in the other two cases (see figure caption). These spectra traces identify the frequency content in the fluctuations. For the $16^{\circ}$ case there are two identifiable spectral peaks--one at very low frequency and the other at a higher frequency. These are discussed further in section 3.4. For the $20^{\circ}$ case, a large concentration of energy occurs at low frequencies al though no clear peak could be identifled. Such low frequency energy gets engulfed in fluctuations over a wider band of irequencies in the $24^{\circ}$ case. At $M_{t}=0.3$, the $20^{\circ}$ diffuser flow appeared audibly louder: thts loudness arising from the low frequency fluctuations was much lower in the $16^{\circ}$ case and appeared "dulled" in the $24^{\circ}$ case. The differences in these unsteady fluctuations are currently under further study and will be reported later.

\subsection{Boundary Layer at the Throat}

The boundary layer momentum thickness at the throat is shown in Fig. 6 as a function of $M_{t}$. Note that the thickness remains the same with or without the diffuser. Measurement at $M_{t}=0.2$ also show that $\theta$ is the same at positive or negative $y$, indicating good symmetry in the flow. The solid line in Fig. 6 represents the equation $\theta / 0_{t}=0.3 /\left(R_{0}\right) 1 / 2$, fitted through an average value of the data at $M_{t}=0.2$ : Red is Reynolds number based on $D_{t}$. The shape factor $H_{12}$ was between 2.2 and 2.3 for all the data. The maximum turbulence was between 3 and 5 percent of $U_{t}$; the turbulence was somewhat higher on the positive $y$ side because of small probe vibrations due to impingement of the flow on the prove stem in that probe configuration. The boundary layer can thus be consldered as "nominally laminar" throughout the $\mathrm{M}_{\mathrm{t}}$ range covered in $\mathrm{Fig}$. 6 . At even higher $M_{t}$ the boundary layer could be turbulent as the Reynolds number based on $\theta$ at $M_{t}=0.4$ is already quite high, about 660. Measurements at higher $M_{t}$ were not attempted because of obvious complications in the hot-wire measurements due to compressibility.

\subsection{Flow Field at $M_{t}=0.3$ for the $16^{\circ}$ Diffuser}

Detalls of the flowfield were measured for the $16^{\circ}$ diffuser at $M_{t}=0.3$. The variation of the static pressure along the centerline is documented in Fig. 7. The continuous increase of $P_{5}$ from the throat downstream indicates the lack of significantly separated flows with the diffuser (see also the discussion of $\mathrm{Fig.} \mathrm{3).} \mathrm{P}_{\mathrm{S}}$ is found to increase rapidly immediately downstream of the throat and then increase gradually farther downstream. This is reconciled by the observed rate of decrease in the core velocity which becomes slower as the exit is approached, as can be seen in Fig. 4. The velocity profiles within the diffuser are shown in $F i g .8(a)$. Note that the profiles in this and some of the following figures have been staggered for easy comparison; in all cases, the ordinate shown pertains to the curve at the bottom. The proflies are top-hat in shape but the boundary layer thickens rapidly with increasing downstream distance. The momentum thickness (mm) was $0.07,0.66,1.37$ and 2.37 at $x / D_{t}=0$. $0.75,1.5$ and 2.25 , respectively; the corresponding shape factor $\left(\mathrm{H}_{12}\right)$ was $2.25,1.82,2.13$ and 2.55, respectively.

The evolution of the full velocity profiles downstream of the diffuser exit are shown in Fig. $8(b)$. The axial variation of the centerline mean velocity and the half-velocity-diameter based on the data of Fig. $8(a)$ and (b) are shown in Fig. 9. One finds that the jet flow downstream of the diffuser exit is still evolving, as the slopes of these curves are changing, and has not reached a self similar state within the $x$-range covered. 8 The longitudinal root mean square fiuctuation intensity proflles. corresponding to the data of Fig. $8(a)$ and $(b)$, are shown in Figs. $10(a)$ and $(b)$.

\subsection{Unsteady Flow Characteristics For the $15^{\circ}$} Diffuser

While the data in section 3.3 oertain to $M_{t}=0.3$, the flow characteristics changed considerably with varying Mach number. An indication of this can be obtained from the data in Fig. 11 . The $u^{\prime}$ intensity was measured at a fixed location at the exit plane while $M_{t}$ was varied. The probe focation was chosen to be off-axis $\left(y / 0_{t}=-0.25\right)$ so that fluctuations due to possible helical mode oscillations could be captured, but close enough 
to the axis to be within the top-hat core flow. At low $M_{t}$ the fluctuation intensity is found to be very large, but diminishes rapidly with increasing $M_{t}$ to a plateau. The intensity essentially remained constant within the $M_{t}$ range of 0.2 to 0.6 . For $M_{t}>0.6$ a large increase in the fluctuation intensity occurred which was accompanied by the generation of a loud, audible tone.

The spectral contents of the u-fluctuations are shown in $\mathrm{Fig}$. 12. At the intermediate $\mathrm{Mt}$ range of 0.3 to 0.6 , the spectra are characterized by two peaks. The one at the higher frequency seems to be assoclated with the jet column instabllity of the ensuing flow. The corresponding Strouhal number based on the throat conditions ( $S t$ = fDt $\left(U_{t}\right.$ ) turns out to be about 0.125 throughout the above $M_{t}$ range. However, when the exit conditions from $F i g .3$ are used, $1 . e$. velocity $\approx 0.5$ $U_{t}$ and jet diameter $\approx 1.4 \mathrm{D}_{\mathrm{t}}$, the corresponding Strouhal number turns out to be 0.35 , reasonably agreeing with data in the literature on the "preferred" frequency of jet column instability. In comparison, the st corresponding to the lower frequency peak is found to be only about 0.008 throughout the $M_{t}$ range of 0.3 to 0.6 . The occurrence of the lower frequency peak is confirmed by spectral analysis within a shorter 0 to $200 \mathrm{~Hz}$ range (data not shown). The origin of these lower frequency fluctuations remains unclear. However, these could be morphologically similar to the phenomenon of low frequency oscillation at incipient separation in the flow over an airfoll studied in Ref. 9.

The $u^{\prime}$-spectra at higher values of $M_{t}$ are shown in the lower part of Fig. 12. The flow in this range is dominated by a tone. The occurrence of the tone was found to be sensitive to ambient and other conditions. For example, placement of the pitut tube stem across the flow near the diffuser exit disrupted the tone and made it much weaker. The amplitude also varied from day to day; in general it was found to occur persistently over the $M_{t}$ range of 0.6 to 0.85 . The value of $S t$ corresponding to the dominant peaks in the spectra traces of Fig. 12 are plotted in Flg. 13 as a function of $M_{t}$. The low frequency component is shown by the square data points. The higher frequency component, due to the jet column instability. is shown by the circular data points with the solid circles representing the tonal oscillation conditions. It is apparent that the tone is a continuation of the jet column instability.

The fundamental ( $p$ lane wave) resonant frequency could be estimated for a driven conical horn representing the $16^{\circ}$ diffuser. Based on the assumption that the resonant frequencies are those with the largest input impedance, a fundamental frequency of $652 \mathrm{~Hz}$ is obtalned for no flow condition. 10 This is somewhat higher but close to the frequencies of the tone observed in Fig. 12 Thus, the tone apparently is set up when the "preferred" frequency of the issuing jet falls close to the acoustic resonance frequency of the conical diffuser.

The nature of the flow fluctuations associated with the spectral peaks of $\mathrm{Fig} .12$ were investigated. Two hot-wires were located at the exit plane, $1.27 \mathrm{~cm}$ away from the axis on either side.
The cross-spectrum and phase between these two signals were measured at various $M_{t}$. Figure $14(a)$ to (c) show such data for $M_{t}=0.11,0.47$ and 0.7 , respectively. The cross-spectrum amplitude (and thus the coherence) is found to be ralatively high at the dominant frequencies in all cases. Note that this is true for both the low and high frequencies in Fig. i4(b). Furthermore, the associated phase values are essentially zero at the frequencies corresponding to these oeaks. This indicates axisymmetric flow oscillations at all these frequencles. (However, a similar measurement for the $20^{\circ}$ diffuser indicated a predominantly non-axisymmetric, flapping motion which is being further investigated.)

The tone at $M_{t}=0.7$ (Fig. $14(c)$ ) also involves an axisymmetric flow oscillation. The corresponding variation of the phase along the axis is shown in Fig. 15. The slope of this curve in the $x / 0_{t}$ range of 3.5 to 5.5 yields a wavelength of $2.6 \mathrm{ot}$. The corresponding phase velocity turns out to be about $0.32 U_{t}$. Thus, the fluctuations are hydrodynamic and not due to, say, an acoustic standing wave. The "mode shape" associated with this $(575 \mathrm{~Hz}$ ) oscillation, at the exit plane, is documented in Fig. 16. The radial variation of the phase and the fundamental root mean square amplitude (uf) are shown by the two curves at the top; the corresponding variation of the mean velocity is shown by the curve at the bottom.

\subsection{Effect of Acoustic Excitation}

Preliminary experiments were done on the effect of acoustic excitation on the unsteady diffuser flow. Excitation at certain high frequencies was found to suppress the fluctuations dramatically. especially at low Mt. The effect of excitation frequency $\left(f_{p}\right)$ on the fluctuations at the exit plane is shown in Fig. 17 for the $16^{\circ}$ diffuser. Clearly, the fluctuations are damped in a range of $f_{p}$ and the band of effective $f_{p}$ shifts progressively with increasing $M_{t}$. At $M_{t}$ higher than 0.2 , very little effect of the excitation could be observed. Referring back to Fig. 11 , one finds that the excitation is effective when the unsteady fluctuations are already high. At the low $M_{t}$, however, the fluctuations are suppressed significantiy. This is also associated with an increase in the pressure recovery coefficient $\left(C_{p}\right)$, by as much as 12 percent. A more pronounced effect of the excitation was observed for the $20^{\circ}$ diffuser which persisted up to about $M_{t}=0.4$.

\section{Concluding Remarks}

The flow through conical diffusers involving transitory stall was investigated experimentally. The steady and unsteady flowfields were compared for three diffusers with total diffusion angles of $16^{\circ}, 20^{\circ}$ and $24^{\circ}$. This was followed by a detalled investigation of the flowfield for the $16^{\circ}$ diffuser. For this case, the $U^{\prime}$-spectrum near the exit was characterized by a peak apparently due to the ensuing jet column instability, at all mach numbers. In the $M_{t}$ range of 0.5 to 0.85 , when the jet column instabllity matched the fundamental acoustic resonance of the diffuser geometry, a seif-sustaining flow oscillation took place, emitting a loud tone. In the range 0.3 to 0.6 , a much lower frequency flow fluctuation could al so be 
detected. The unsteady fluctuations at all these frequencies were found to be primarily axisymmet$r i c$ in nature for the $16^{\circ}$ diffuser. For $M_{t}<$ 0.2 , the flow fluctuations near the exit were unusually large in amplitude. In this range of $M_{t}$, acoustic excitation was found effective in reducing the fluctuations. This was accompanied by an increase in the pressure recovery coefficient. Reflecting on the overall results various aspects of the unsteady flow appear intriguing and deserve further comment. First, the dramatic increase in the flow fluctuation levels as $M_{t}$ is decreased below about 0.2 is rather puzzling. It appears that the change in boundary layer characterlstics at the throat may be causing the flow to behave differently. However, such a change is not clearly discernible. With decreasing $M_{t}$ only the boundary layer thickness has increased, al though it is still quite thin, e.g., $D_{t} / \theta \approx 400$ at $M_{t}=$ 0.1 . The shape factor and turbulence intensity. on the other hand, have not changed significantly. Second, the occurrence of the low frequency spectral peak in the intermediate $M_{t}$ range for the $16^{\circ}$ diffuser needs further study. As mentioned in the text this could be similar in origin to the low frequency fluctuation in the flow over airfolis. 9 Third, the preliminary data lllustrate a drastic change in the nature of the low frequency fluctuations between the $16^{\circ}$ and the $20^{\circ}$ diffusers. The fluctuations are axisymmetric in the $16^{\circ}$ case and the spectrum exhibited a clear peak. In the $20^{\circ}$ dfffuser, the fluctuations became flapping type and the spectrum did not have identifiable low frequency peak $(s)$. These aspects together with the effect of the acoustic excitation for all three diffusers are currently under further investigation.

\section{References}

1. Bradley, C.I., and CookrelI, D.J. "The Response of Diffusers to Flow Conditions at The ir Inlet," Symposium on Internal Flows. University of Salford, Lancaster, England, 1971 pp. A32-A41.

2. Thompson, R.G., "Performance Correlations for Flat and Conical Diffusers," ASME Paper 79-GT-52, Mar. 1979.

3. Markland, E., and North, P., "Performance of Conical Diffusers up to the Choking Condition," 6th Conference on Fluid Machinery, Vol. 2, L. Kisbocskoi and A. Szabo, eds., Akademiai Kiado, Budapest, Hungary, 1979, pp. 703-714.

4. Ashjaee, J., and Johnston, J.P., "StraightWalled, Two-Dimensional Diffusers -- Transitory Stall and Peak Pressure Recovery," Journal of Fluids Engineering, Vo1. 102. No. 3, Sept. 1980 . po. 275-282.

5. Wysocki, W., and Kazimierski, 2., "Analysis of Subsonic Transitory Stalled flows in Straightwalled Diffusers," Journal of Fluids Engtneering. Vol. 108, No. 2, June 1986, pp. 222-225.

6. Rice, E.J., and Zaman, K.B.M.Q., "Control of Shear Flows by Artificial Excitation." AIAA Paper 87-2722, OCt. 1987. (NASA TM-100201).
7. Raman, G., Zaman, K.B.M.Q., and Rice, E.J., "Initial Turbulence Effect on Jet Evolution with and Wi thout Tonal Excitation," Physics of Fluids A, Vol. 1, No. 7. July 1989, pp. 1240-1248.

8. Zaman, K.B.M.Q., "Flow Field and Near and Far Sound Field of a Subsonic Jet," Journal of Sound and Vibration, Vol. 106, No. 1, Apr. 8, 1986, pp. $1-15$

9. Zaman, K.B.M.Q., McKinzie, D.J., and Rumsey, C.L., "A Natural Low-Frequency Oscillation of the Flow Over an Airfoil Near Stalling Conditions," Journal of Fluid Mechanics,

Vol. 202, May 1989, pp. 403-442.

10. Kinsler, L.E., and Frey, A.R., "Fundamentals of Acoustics," Second Edition, John Wiley \& Sons Inc., New York, 1962.

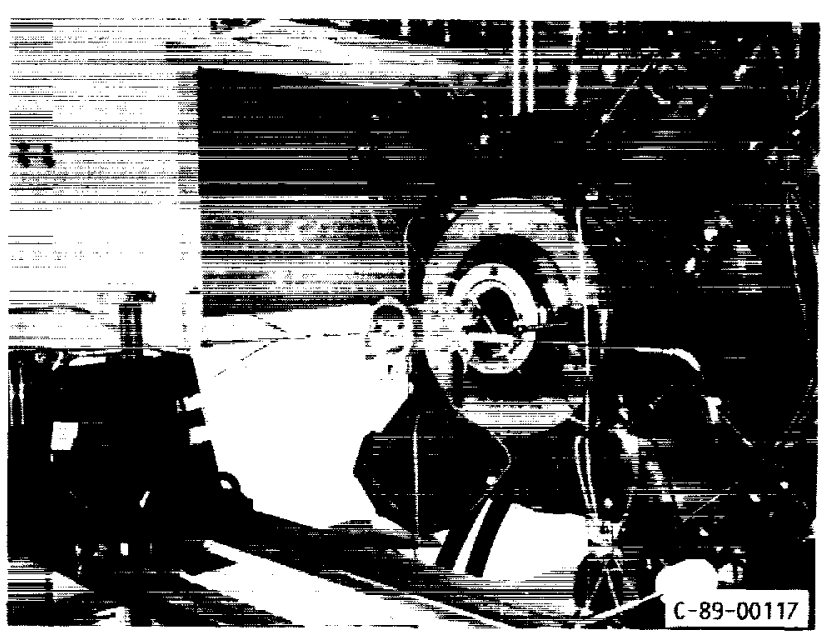

FIGURE 1A, - PHOTOGRAPH OF FLOW FACILITY.

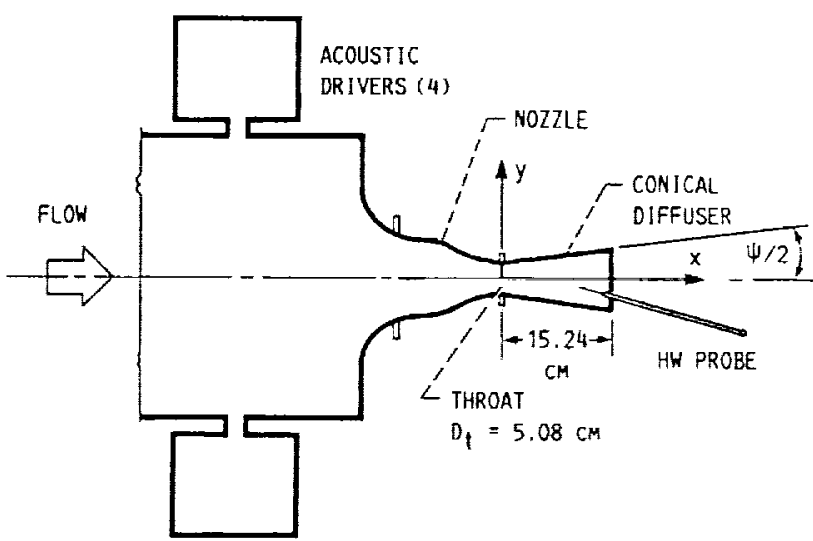

FIGURE 1B. - SCHEMATIC OF FLOW FACILITY 

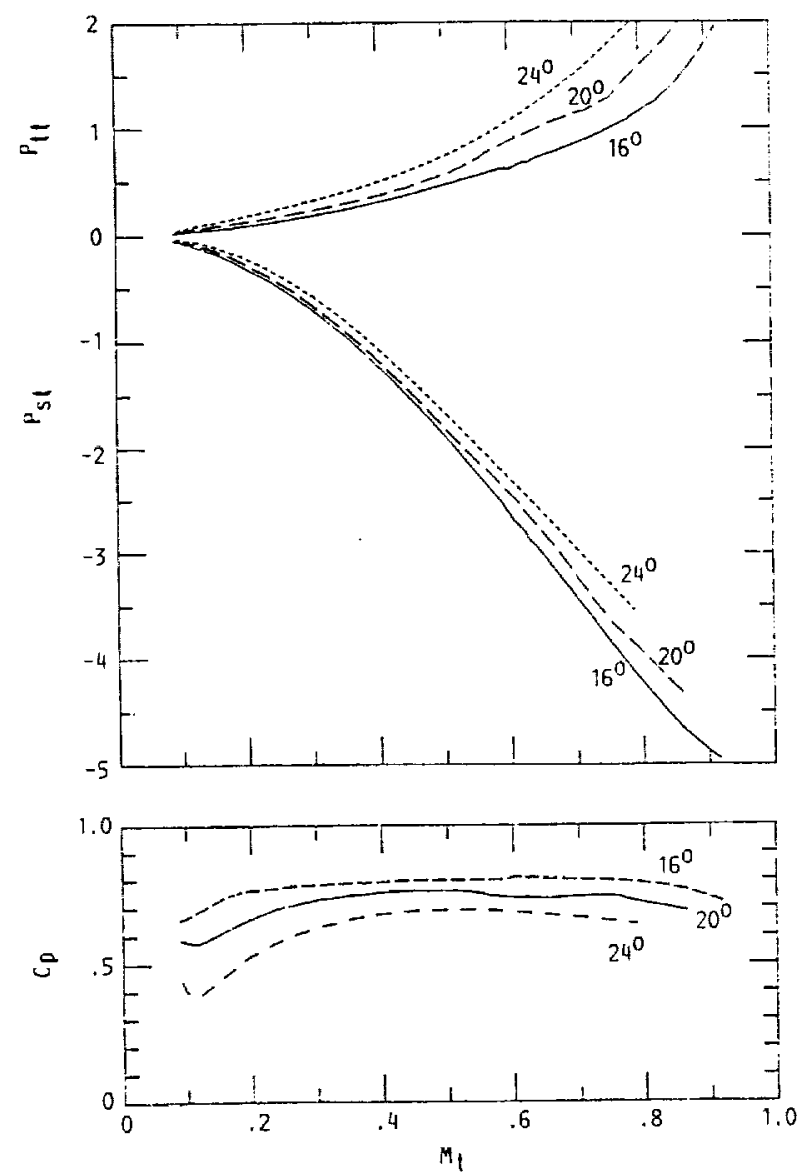

FIGURE 2. - VARIATIONS OF TOTAL ( $\left.P_{t}\right)$ AND STATIC $\left(P_{\text {st }}\right.$ ) PRESSURES (PSIG) AT THROAT. AND THE PRESSURE RECOVERY COEFFICIENT $\left(C_{p}\right)$ WITH THROAT MACH NUMBER $\left(M_{l}\right)$ FOR THE THREE DIFFUSERS.
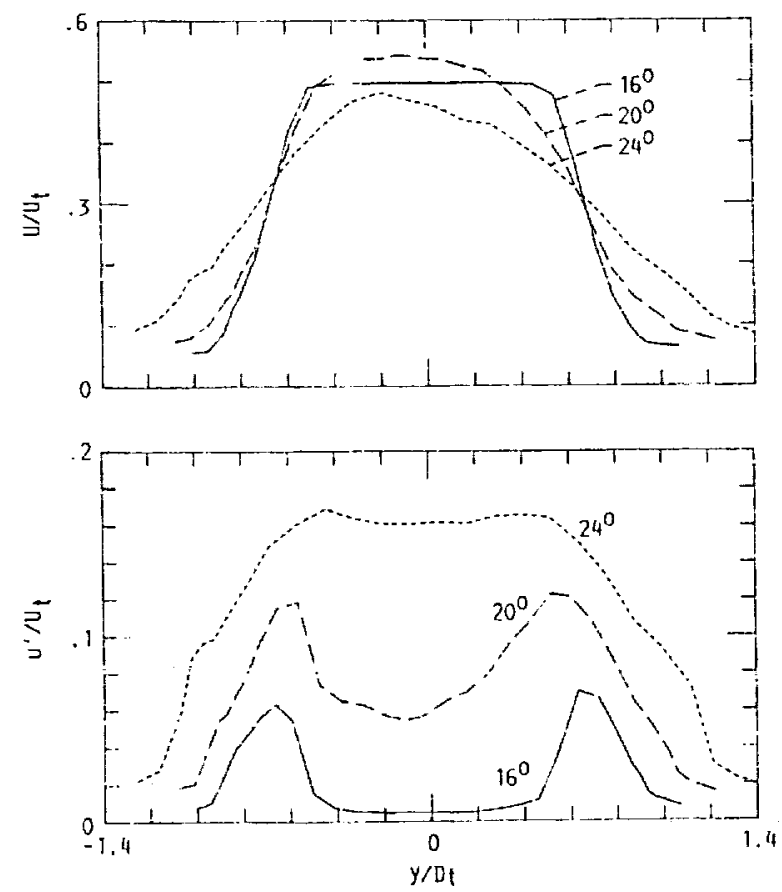

FIGURE 3. - DIAMETRAL PROFILES OF LONGITUDIMAL MEAN VELOCITY (UI) AND R.M.S. FLUCTUATION (U') INTENSITY AT THE EXIT OF THE DIFFUSERS AT $M_{1}=0.3$.
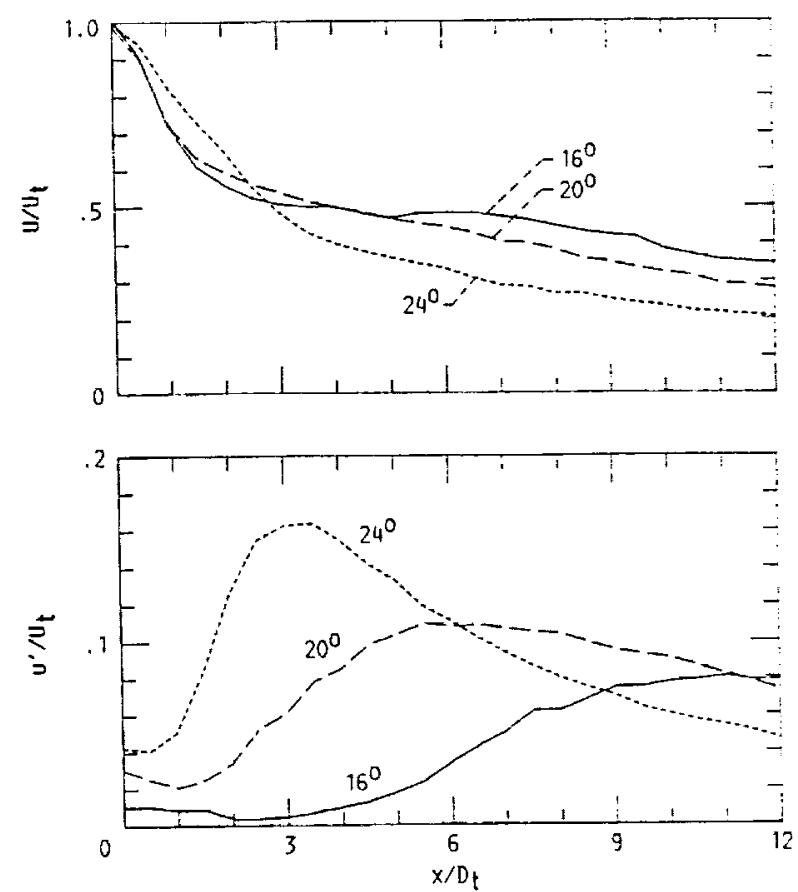

FIGURE 4. - VARIATIONS OF U AND U' ALONG THE AXIS OF THE DIFFUSERS. AT $M_{t}=0.3$.

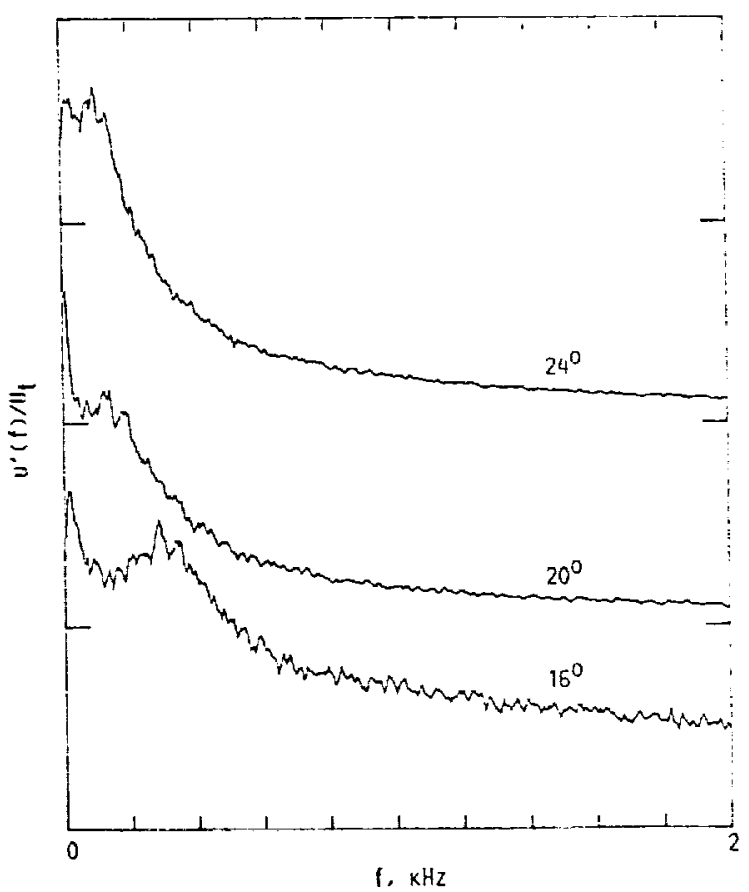

FIGURE 5. - $u$ ' SPECTRA MEASURED AT THE EXIT PLANE, $1.27 \mathrm{CM}$ OFF AXIS. ARBITRARY VERTICAL SCALES. PEAK LEVELS OF $U^{\circ}(\mathrm{l}) / U_{\text {t ARE }} 0.0007,0.013$ AND 0.031 FOR THE $15^{\circ}, 20^{\circ}$ AND $24^{\circ}$ DIFFUSERS, RESPECTIVELY. $M_{t}=0.3$ FOR $24^{\circ}$ AND $20^{\circ}$ CASES, $M_{t}=0.36$ FOR THE $16^{\circ}$ CASE. 


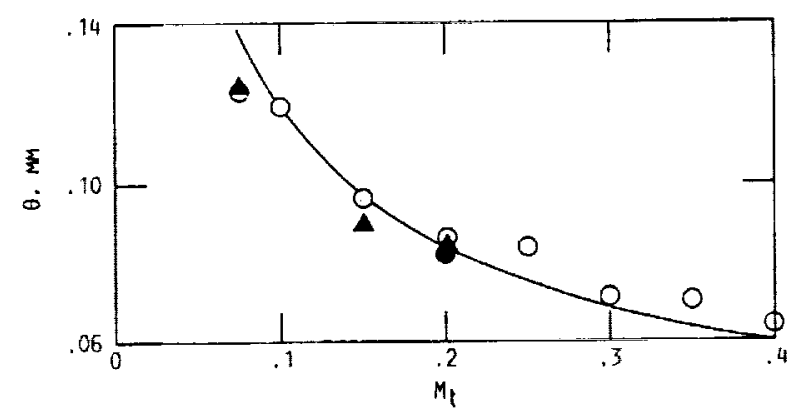

FIGURE 6. - BOUNDRY LAYER MOMENTUM THICKNESS $(\theta)$ AT THE THROAT vs. Mt. O. MEASUREMENT AT EXIT OF NOZZLE WITHOUT A DIFFUSER; $\triangle$. AT THE THROAT WITH THE $16^{\circ}$ DIFFUSER ON. SOLID SYMBOLS FOR MEASUREMENT AT POSITIVE $Y$, OPEN SYMBOLS FOR NEGATIVE $Y$.

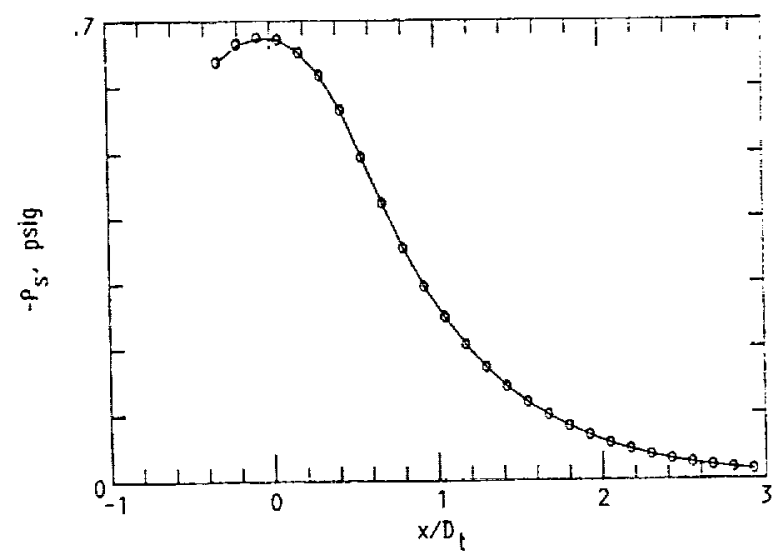

FIGURE 7. - STREAMHISE VARIATION OF STATIC PRESSURE WITHIN THE $16^{\circ}$ DIFFUSER. MEASURED ALONG THE AXIS. AT $M_{1}=0.3$.
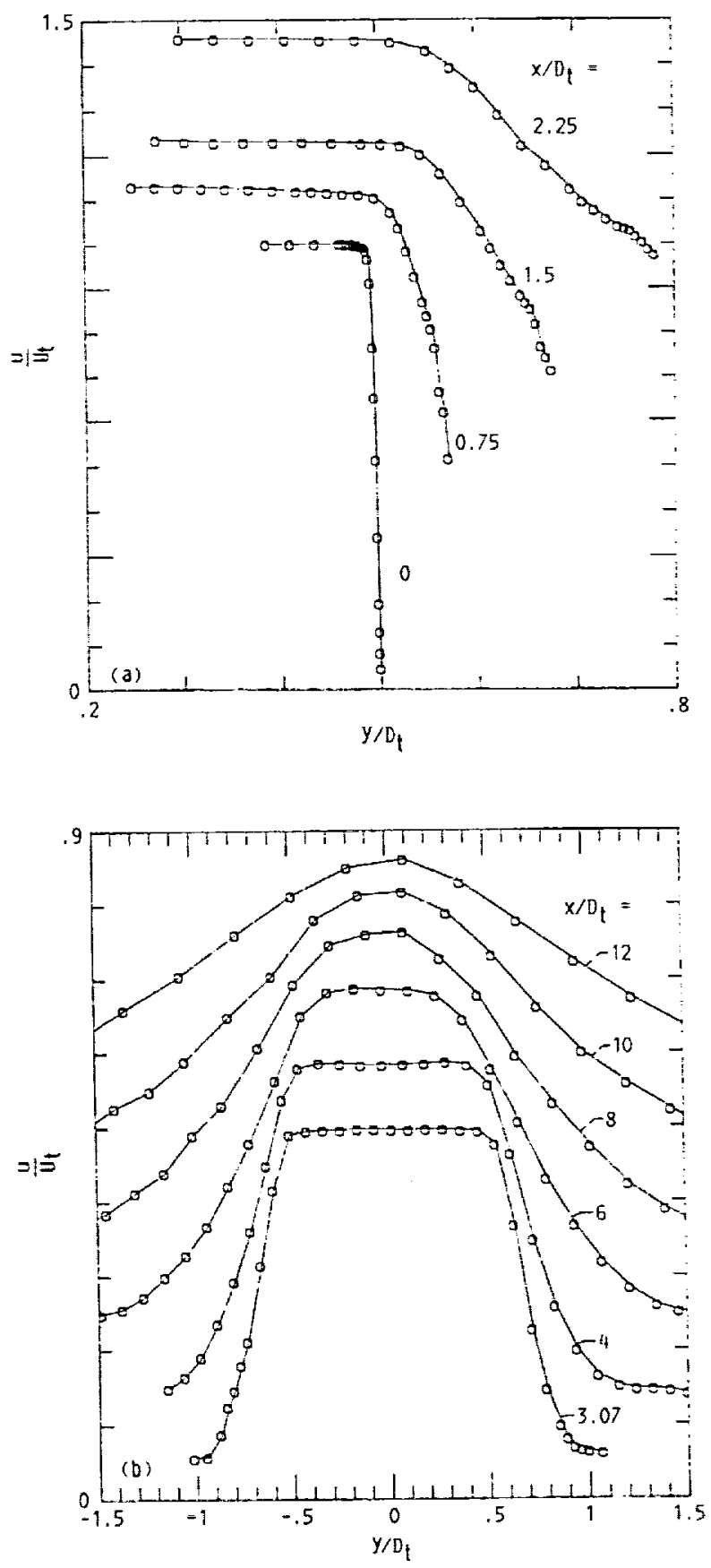

FIGURE $8 .-U(y)$ PROFILES at $M_{1}=0.3 ; 16^{\circ}$ DIFFUSER. CURVES ARE STAGGERED BY ONE MAJOR ORDINATE DIVISION. (a) PROFILES WITHIN THE DIFFUSER, (b) PROFILES DOHNSTREMM OF THE EXIT. 


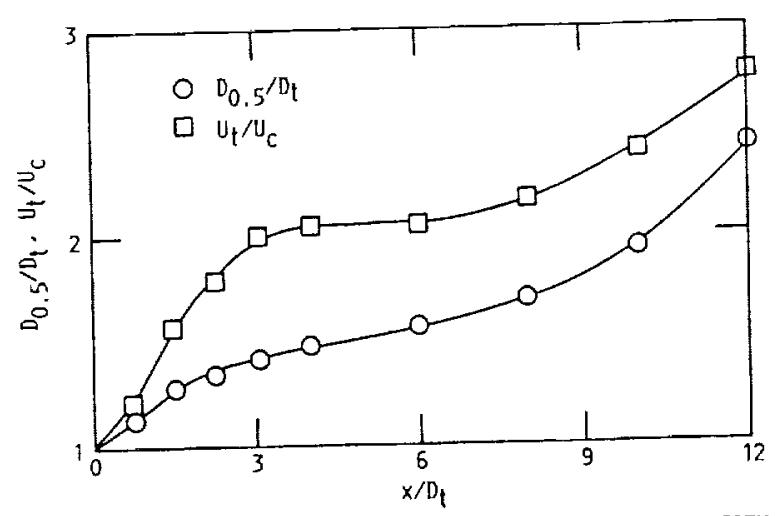

FIGURE 9 - STREAMWISE VARIATION OF: $O$. HALF VELOCITY DIAMETER, $D_{0.5}$, AND $\square$. CENTERLINE MEAN VELOCITY (INVERSE), $U_{C}$.
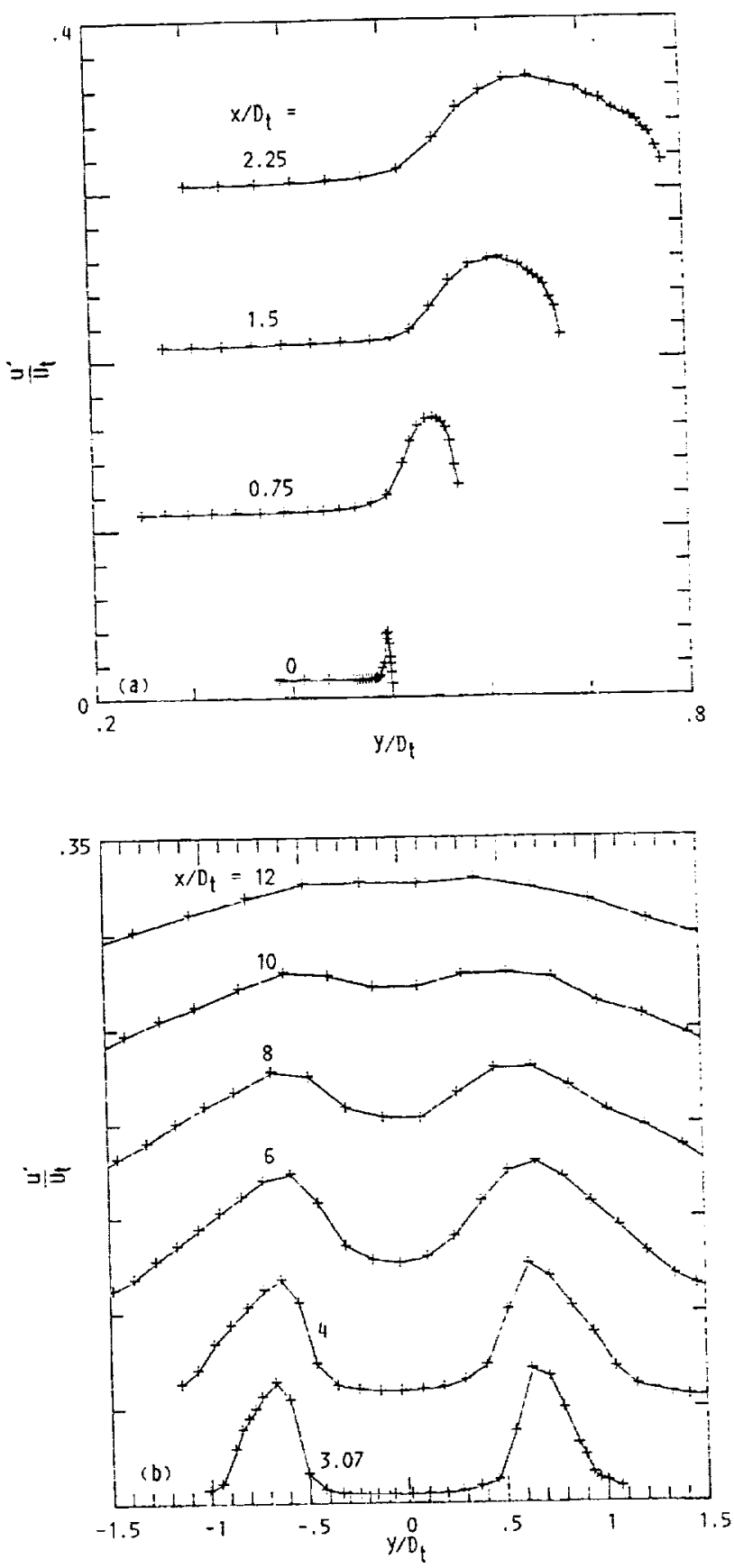

FIGURE 10. $-u^{\prime}(y)$ PROFILES CORRESPONDING TO THE DATA OF FIGS, 8 (a). (b). 

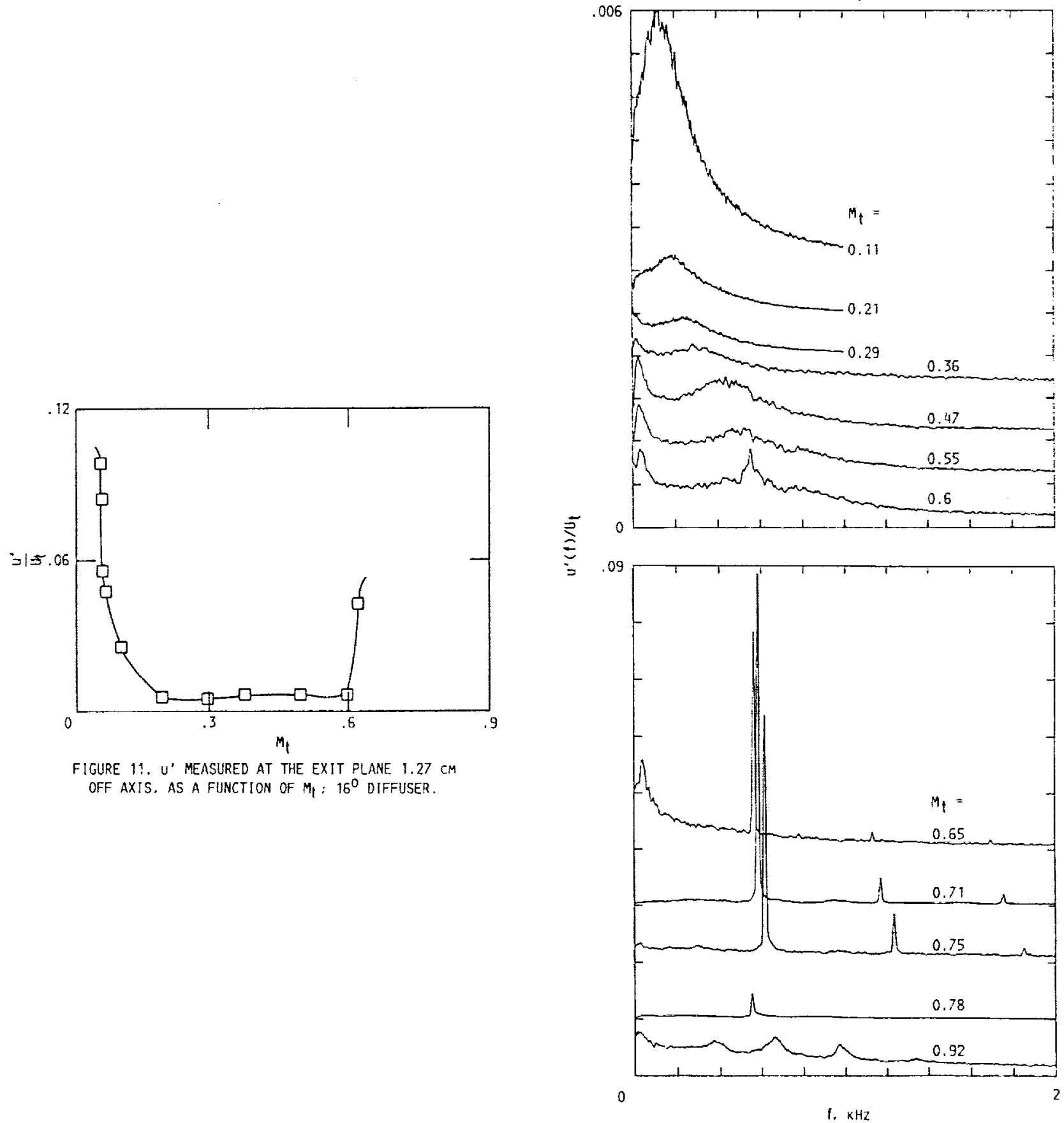

FIGURE 11, U' MEASURED AT THE EXIT PLANE $1.27 \mathrm{cM}$ OFF AXIS. AS A FUNCTION OF Ml: $16^{\circ}$ DIFFUSER. 

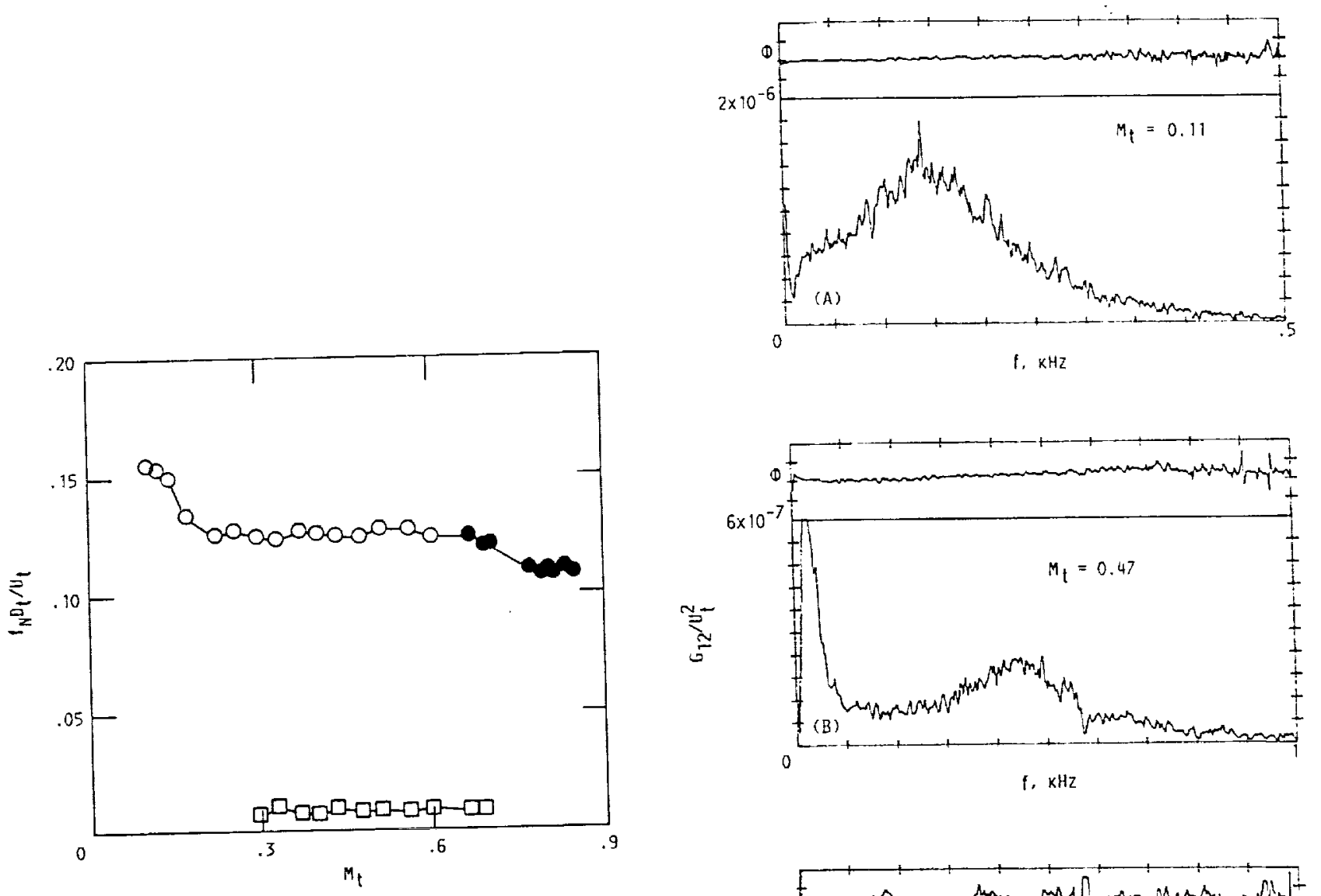

FIGURE 13. - STROUHAL NUMBER CORRESPONDING TO THE SPECTRAL PEAKS (AS IN FIG, 12) VERSUS $M_{t}$. SOLID DATA FOR SELF SUSTAINING TONES: SQUARES FOR THE LOWER FREQUENCY SPECTRAL PEAKS.

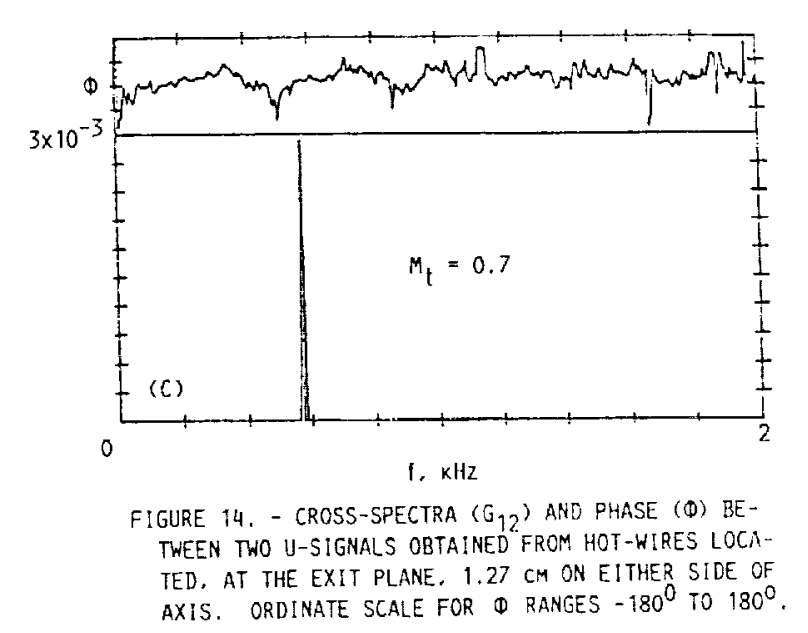




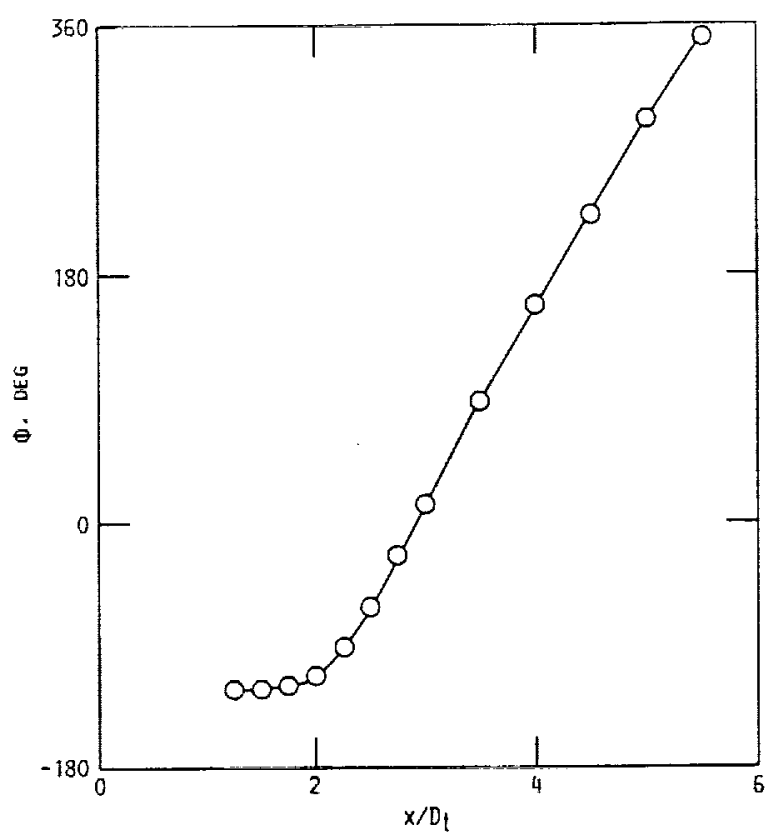

FIGURE 15. - STREAMHISE VARIATION OF PHASE OF THE $575 \mathrm{~Hz}$ TONE AT $M_{1}=0.7$. DATA BASED ON U-SIGNAL ON AXIS: $16^{\circ}$ DIFFUSER.
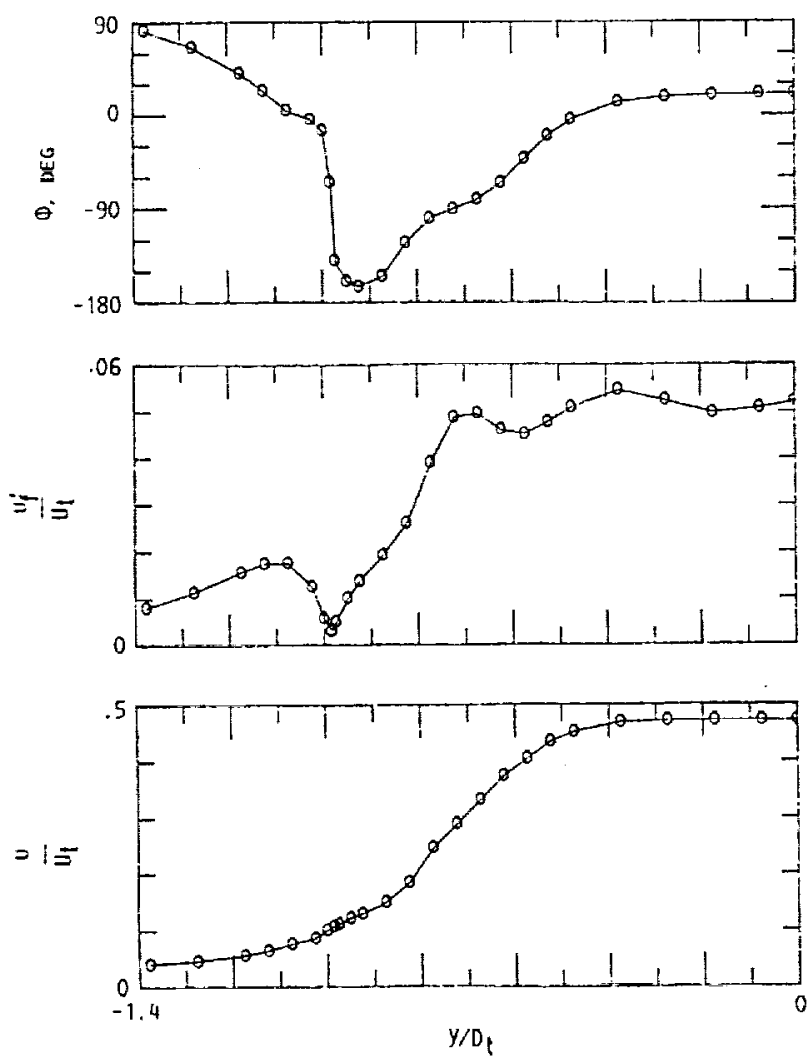

FIGURE 16. - RADIAL PROFILES OF U. U' AND $D$ FOR THE $575 \mathrm{~Hz}$ TONE AT $M_{t}=0.7$. MEASUREMENT AT EXIT, $x / D_{t}=3.07: 16^{\circ}$ DIFFUSER.

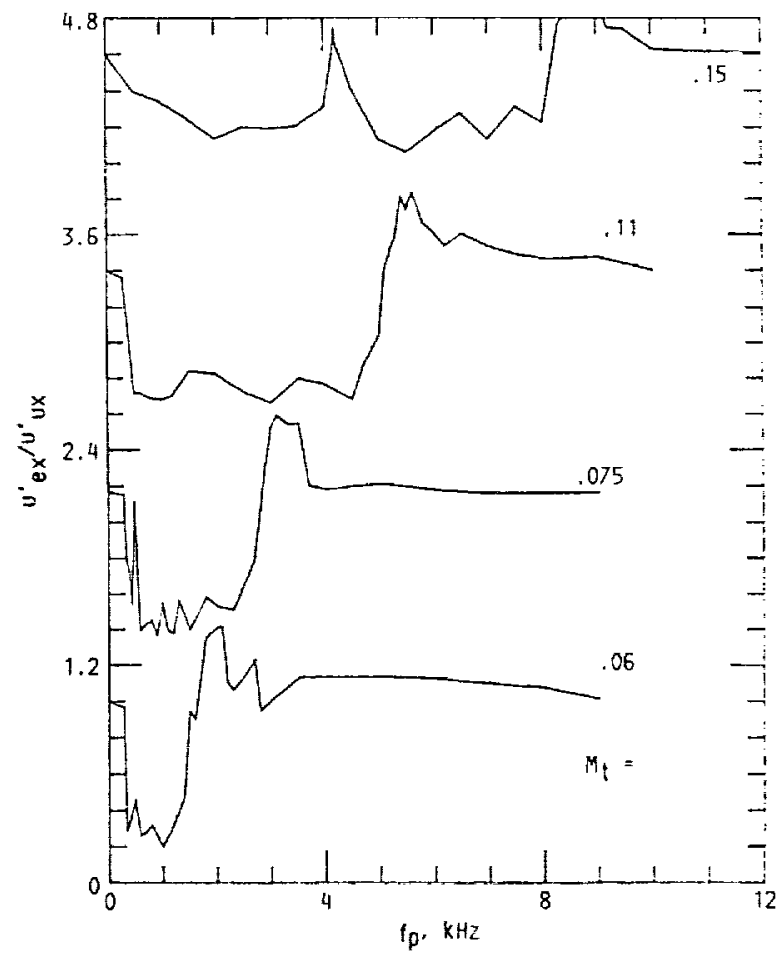

FIGURE 17. - RATIOS OF TURBULENCE INTENSITIES WITH AND WITHOUT EXCITATION. MEASURED AT THE EXIT PLAN $1.27 \mathrm{cM}$ OFF AXIS. FOR VARYING EXCITATION FREQUENCY $i p$. CURVES ARE STAGGERED BY ONE MAJOR OREINATE DIVISION: $16^{\circ}$ DIFFUSER. 


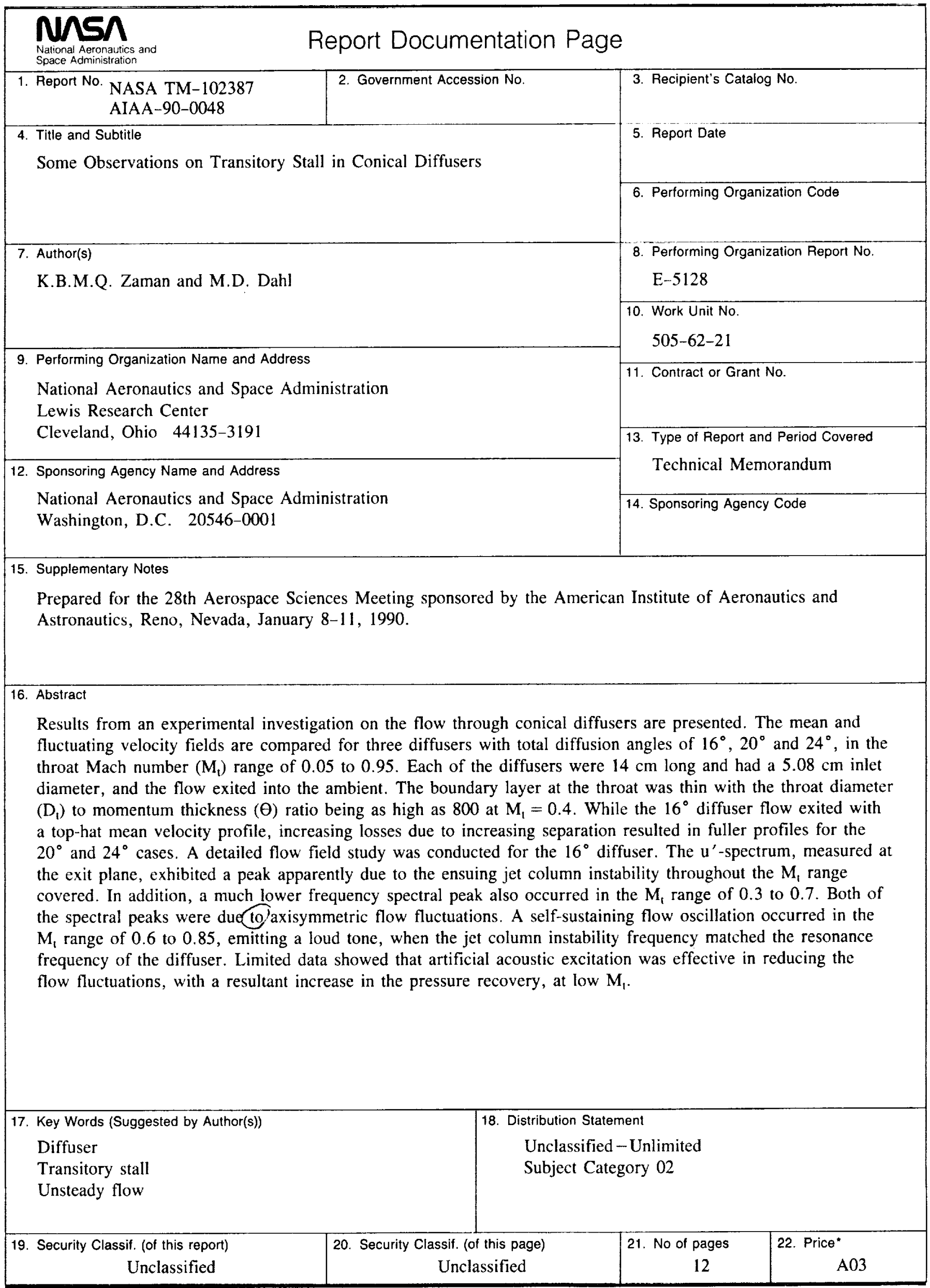


